\title{
Key Universal Activities of Mathematical Learning in Problem Solving Mathematics Classroom
}

\author{
Saastra Laah-On ${ }^{1}$, Pimpaka Intaros ${ }^{2}$, Kiat Sangaroon ${ }^{3}$ \\ ${ }^{1}$ Master Program in Mathematics Education, Faculty of Education, Khon Kaen University, Khon Kaen, Thailand \\ ${ }^{2}$ Doctoral Program in Mathematics Education, Faculty of Education, Khon Kaen University, Khon Kaen, Thailand \\ ${ }^{3}$ Faculty of Science, Khon Kaen University, Khon Kaen, Thailand \\ Email: saastra_l@hotmail.com
}

Received September 25 ${ }^{\text {th }}$, 2013; revised October 25 ${ }^{\text {th }}$, 2013; accepted November $2^{\text {nd }}, 2013$

\begin{abstract}
Copyright (C) 2013 Saastra Laah-On et al. This is an open access article distributed under the Creative Commons Attribution License, which permits unrestricted use, distribution, and reproduction in any medium, provided the original work is properly cited.
\end{abstract}

\begin{abstract}
To enhance students' problem solving potential, an important skill for 21st century, teachers should concern what kinds of authentic-mathematics experiences that students can get through problem solving (Cai, Mamona-Downs, \& Weber, 2005). In addition, mathematics classroom approach has changed radically from a drill-and-practice approach to more insight-based problem oriented approach (Van Oers, 2002). According to a problem solving mathematics classroom, in which an open approach is used as a teaching approach, students are required to adapt what they have learned to solve problem situations (Inprasitha, 2010). These problem situations are designed based on students' experiences. Regarding these points, a purpose of this study was to investigate key universal activities, which are based on Bishop (1988) who presented the key universal activities as foundations for students' mathematical learning. Case study was employed in this study. Video and audio tape recording, and field note taking were used as methods for collecting data of a targeted group including six of grade 1 students in 2010 academic year of a school participating the Project for Professional Development of Mathematics Teachers through Lesson Study and Open Approach. Data were analyzed by using descriptive statistic and analytic description. The results showed that there were various key universal activities in each problem situation occurring in problem solving mathematics classroom. These key universal activities have been enhancing the students to solve the problems efficiently.
\end{abstract}

Keywords: Key Universal Activities; Problem Solving Classroom; Open Approach; Lesson Study

\section{Introduction}

In the 21st century, there are more increasing of a complexity of problems that one could encounter, both in a country and in the world. This has been requiring more dedication of preparing students to be problem solvers as providing the students to learn some strategies that could help them to cope with such problems (Barell, 2010). The purpose of learning has not been knowledge itself, but rather that the students should have abilities to learn in every time and develop themselves constantly (Bellanca \& Brandt, 2011). Therefore, classrooms must be changed from "traditional classroom" that devotes most of instructional time to teacher's recitation and practices, to "reform classroom" that provides wider task demand to inquire students' effective problem-solving strategies and communication practices (Forman, 1996). According to this point, what is critical is not whether the teachers should use problem solving as an approach to teach mathematics, but rather what kinds of authentic experiences concerning mathematics that students can get through problem solving (Cai, Mamona-Downs, \& Weber, 2005). Recently, the classroom approach to mathematics has changed radically from a drill-and-practice approach to more insight-based problem oriented approach. In other words, the problem solving approach to mathematics is introducing stu- dents into the culture of mathematics practice (Van Oers, 2002).

In socio-cultural points of view, as Bishop (1988) has realized that mathematics is a cultural phenomena, a mathematical enculturation process then is a process in which concepts, meanings, processes and values are shaped according to certain manner, and also emphasizing on social context where there is an interaction between those who participate in this process. The goal of this process is developing a way of knowing in each individual by promoting the transformation from technique or a way of doing to meaning or a way of knowing. Therefore, it is an intentional process of shaping ideas. Moreover, this process is based on experiences formed in key universal activities that are counting, measuring, locating, designing, building, playing, and describing. These activities are the foundations for the development of students' mathematical ideas. In other words, these activities promote the transformation from technique, or a way of doing, to meaning, or a way of doing.

A mathematics classroom using an open approach (Figure 1) as a teaching approach which encourages the students to learn mathematics by themselves along 4 phases are composed of 1 ) Posing open-ended problem, 2) Students' self learning, 3) Whole class discussion and comparison, and 4) Summarization through connecting students' mathematical ideas emerging in 


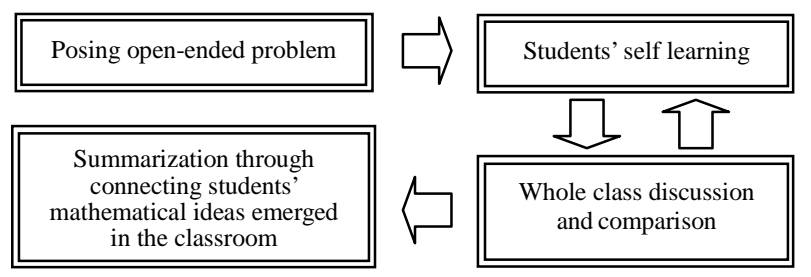

Figure 1.

Open approach as a teaching approach (Inprasitha, 2010).

the classroom (Inprasitha, 2010).

Illustration of classroom activities using the open approach (Table 1) could be described as 1) Posing open-ended problem - the open-ended problems or problem situations are posed in the classroom and the students are often asked about a meaning of the problems and challenged to solve the problems; 2) Students' self learning - this phase consists of a combination of two parts: individual work and discussion by the whole class; 3) Whole class discussion and comparison-the students' activities are crucial to further development of a lesson in which the teacher should try to identify those students who do not understand the problems and provide more suggestions to stimulate the students in a whole class to think according to the problems; and 4) Summarization through connecting students' mathematical ideas emerging in the classroom - the teacher should include all students' prepositions and concentrate on one point view, lead to a conclusion by integrating and arranging them according to particular point of view, and also facilitate a smooth transition to the next lesson (Inprasitha, 2010).

Moreover, the teachers mostly start the classes with a problem situation which is designed by using open-ended problems and is closed to the students experience or what the students have learned, and the learning organization in this classroom is considered as a interaction process between a teacher and students, and among students themselves where the teacher orchestrate the students' mathematical ideas resulted from promoting the students to think and solve the problems in their own way. Therefore this process can be described by social and cultural aspects (Inprasitha, Pattanajak, \& Prakaikam, 2007). These mean that the approach in this classroom necessarily nurtures the students to learn mathematics in meaningful ways according with the students own experiences.

As a result, what is needed for the teachers or mathematical cultivator is a broad understanding of mathematics as a cultural phenomena (Bishop, 1988). Therefore, the teachers should be conscious about what kind of experiences the students could learn best in mathematical culture. According to these points, deep insight of the problem solving mathematics classroom is very important for the teachers. Lesson study, consequently, is necessary for the teachers to do their practices along with a cycle of the lesson study (Figure 2). Collaboratively observing the research lesson (Do) and collaboratively reflecting on teaching practice (See) would support the teachers to comprehend their classroom where they could analyze the activities occurring in the classroom and promote the students' learning according with the activities.

\section{Research Methodology}

\section{Theoretical Frameworks}

The theoretical frameworks used to conduct this research

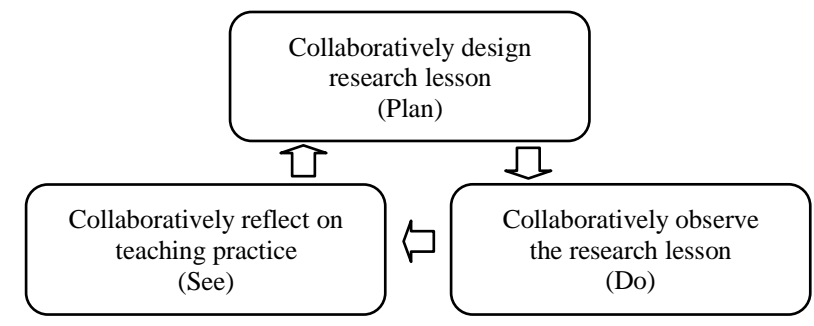

Figure 2.

Lesson study in Thailand (Inprasitha, 2010).

were composed of 2 theoretical frameworks; 1) Open Approach as a Teaching Approach (Inprasitha, 2010) used to analyze phases of the classroom that emphasize on problem solving, and 2) Key Universal Activities (Bishop, 1988) used to analyzed activities occurred in each phase of the classroom whether these activities composed of the key universal activities which are the foundations for students' mathematical learning.

\section{Objective of the Study}

This research was aimed to investigate key universal activities, in which are the foundations for students' mathematical learning based on Bishop (1988), in the problem solving mathematics classroom, in which the open approach is used as the teaching approach based on Inprasitha (2011), that would yield more realization for the teachers of how to promote the students' learning in meaningful ways.

\section{Target Group of the Study}

The target group in this research included six of grade 1 students, who were studying at Ban Bueng-neum-bueng-krai-noon School, Khonkaen province, and attending 5 learning activities of the Length Comparison learning unit in the second semester of the 2010 school year. The school has been participating in the Project for Professional Development of Mathematics Teachers through Lesson Study and Open Approach since 2007 school year, the teachers have been organizing learning activities by using the open approach as a teaching approach which is supervised by the Center for Research in Mathematics Education (CRME), Khon Kaen University.

\section{Data Collection and Analysis}

In this research, the lesson study team, including the teacher, observing teachers, the author as a researcher, and a researcher assistant, cooperatively designed the learning activities by using a Japanese textbook "Study with Your Friends Mathematics for Elementary School 1st grade” which emphasizing on "students' how to learn" that supports students' self learning (Inprasitha, 2010). Several methods were used to collect and analyze the data in the classroom; video and audio recording, and field note taking were used as methods for collecting data, the collected data were then analyzed by using descriptive statistic and presented by using analytic description.

\section{Results and Discussions}

In the problem solving mathematics classroom of the learning unit of comparing length, there were all of 6 key universal 
Table 1.

Classroom activities using the open approach.

\begin{tabular}{|c|c|c|}
\hline & Teacher's Actions & Students’ Responses \\
\hline Posing open-ended problem & $\begin{array}{l}\text { Ask about a meaning of the problems and } \\
\text { challenge to solve the problems }\end{array}$ & $\begin{array}{l}\text { Interpret problem situations, address their problem } \\
\text { and speak out loud }\end{array}$ \\
\hline Students' self learning & Collect emerging students' ideas & $\begin{array}{c}\text { Find their own problem resolutions and prepare to } \\
\text { discuss with other students }\end{array}$ \\
\hline Whole class discussion and comparison & $\begin{array}{l}\text { Conduct discussion and sometimes share ideas } \\
\text { with students }\end{array}$ & Present and discuss ideas \\
\hline $\begin{array}{l}\text { Summarization through connecting students' } \\
\text { mathematical ideas emerged in the classroom }\end{array}$ & Highlight and summary students' ideas & $\begin{array}{l}\text { Take and share ideas with teacher and other } \\
\text { students }\end{array}$ \\
\hline
\end{tabular}

activities occurred in the classroom and there are variously key universal activities occurred in each phase of the classroom as shown in the table as follows.

Information (Table 2) revealed that all kinds of key universal activities occurred in the problem solving mathematics classroom especially in the phase of Students' self learning in which the students were encouraged to think about the problem situations and solve the problems by themselves, although there was no the key universal activity occurred in some phases of the classroom. Examples of those scenarios which the students participate each key universal activity as follows.

\section{Counting Activity}

In the activities of constructing a paper chain that the students in each group cooperated to make the paper chain and comparing them among all groups, the students discussed about how to compare paper chains' length. The students tried to solve the problem related to a certain number of the papers used to make paper chain whereby they started to count one by one, and then changed to count by two pieces of papers while they were struggling in re-counting the papers, as a following protocol.

Student A: 39 and then 40.

Student B: 48, 49, 50.

Teacher: Oh, why all of you didn't get the same number of paper?

Student C: Let's count them again.

Student B: 2, 4, 6, 8, 12, 14, 16, 18. (Student B stopped to count.)

\section{Measuring Activity}

In the activities of comparing a length of two strings which were straight and tied, respectively, one of the students compared two strings' length. The student tried to solve the problem related to length comparison whereby she untied the string first and compared them directly as putting the strings' end to be on the same level. This was resulted from her experience in an activity of comparing two straight things (pencils) and identifying which one was longer, as a following protocol.

Teacher: Okay, there are two strings here. Which one is longer? (Figure 3)

All students: Red./Blue.

Teacher: How could we do? (Student F brought the strings from the teacher and then put a couple of their ends on the same level.)

Student D: Untie that string. (Figure 4)

Teacher: Like this? (Student F untied the string, and then stretched them from the bottom to the up side.)

\section{Locating Activity}

In the activities of measuring and comparing the students' part of body and the students have to put a ribbon represented their arms' length on a presenting paper, one group of the all the students' groups tried to solve the problem related to referring point whereby they used an upper edge of the presenting paper to be the referring point for making these two lines were parallel and easy for comparison. This was resulted from their experience in an activity of comparing two strings that have to put their ends on the same level, as a following protocol.

Student B: (Student B was putting the ribbon representing a length of her arm on the presenting paper)

Student A: It's enough? (Student A asked student B who was putting the ribbon representing a length of her arm on the presenting paper).

Student B: Hey, it's not straight. (Student B tried to stretch the ribbon after she used the upper edge of the presenting paper to be the starting point of comparing the ribbons.)

\section{Designing and Building Activity}

In the activities of comparing the ribbon represented the length of the students' arms on a presenting paper, the students tried to solve about geometric attribute whereby they put one of the ends of the ribbon on a point beyond a starting point of the presenting paper by using tessellation, since the length of her arm was longer than the presenting area. This was resulted from their experience in an activity of comparing two strings while they were adapting to change the starting points for comparing them, as a following protocol.

Student D: Why is a paper not enough? (Student D asked the teacher after she put the ribbon representing a length of her arm on the presenting paper by put one of the ribbon's ends on the same line of perpendicular line in the presenting paper.)

Teacher: Does it mean that your arms are longer than the presenting paper?

Student D: (Student D moved out the ribbon from the presenting paper and tried to put it back on the presenting paper.)

Teacher: Where is it? (Figure 5) (Student D put the ribbon on the presenting paper again whereby putting one of the ends beyond the perpendicular line in the presenting paper.)

\section{Playing Activity}

In the activities of constructing a paper chain, one group of the all the students' groups tried to solve the problem related to 
Table 2.

Percentile of occurrence of the key universal activities in each phase of the classrooms.

\begin{tabular}{|c|c|c|c|c|c|}
\hline & $\begin{array}{l}\text { Posing Open-Ended } \\
\text { Problem }\end{array}$ & $\begin{array}{l}\text { Students' Self } \\
\text { Learning }\end{array}$ & $\begin{array}{c}\text { Whole Class } \\
\text { Discussion and Comparison }\end{array}$ & $\begin{array}{l}\text { Summarization } \\
\text { through Connection }\end{array}$ & Percentile of Occurrence \\
\hline Counting & 0 & 3.96 & 1.98 & 0.99 & 6.93 \\
\hline Measuring & 10.9 & 21.78 & 17.82 & 1.98 & 52.48 \\
\hline Locating & 0.99 & 9.9 & 2.97 & 0 & 13.86 \\
\hline Designing and Building & 0.99 & 2.97 & 0 & 0 & 3.96 \\
\hline Playing & 0 & 1.98 & 0 & 0 & 1.98 \\
\hline Describing & 7.92 & 4.95 & 3.96 & 3.96 & 20.79 \\
\hline Total & 20.8 & 45.54 & 26.73 & 6.93 & 100 \\
\hline
\end{tabular}

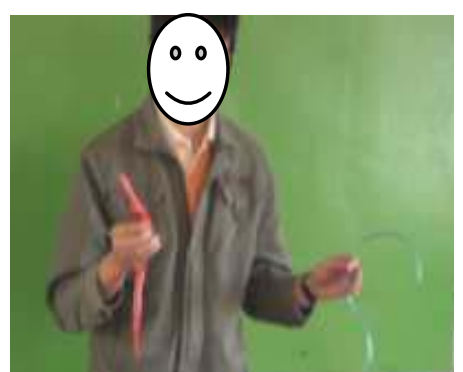

Figure 3.

Teacher used ribbon strings as instructional material.

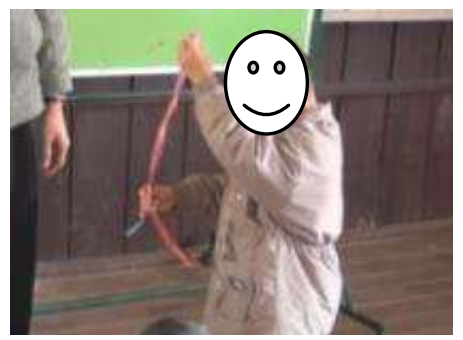

Figure 4.

Student compared length between 2 ribbon strings.

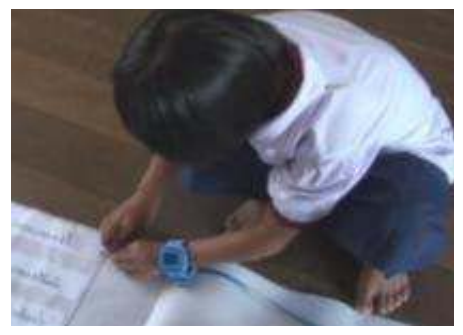

Figure 5.

Student put down a ribbon sting on representing paper.

planning and rule whereby one of the students in the group planned for taking less time of making the paper chain by asking another students to put some glue on the ends of papers before she will compound them together, as a following protocol.
Student E: I can't compound them.

Student D: Yes, we can. (Student D glued one side of the paper' ends.) Glue it like this, I will compound them. (Student $\mathrm{D}$ asked student $\mathrm{E}$ to glue the papers.)

\section{Describing Activity}

In the activities of comparing a length of two strings and the students have to show their reasons to support their answer, one of the students tried to solve the problem related to reasoning whereby she put one couple of the strings' ends on the same level and then the difference of the couple strings was shown. This could enhance her describing reasonably of which one was longer, as a following protocol.

Teacher: What should be in the same level? (Student D stretched the strings whereby one couple of the ends was in the same level.) Oh, is here be in the same level? What's about the longer one?

Student D: This part is over then... (Figure 6) (Students D folded the remainder part down at the shorter one's end.)

\section{Conclusion}

This information could be the empirical evidences which support an important characteristic of a new approach used in the problem solving-mathematics classroom that provides the opportunity for the students to learn mathematics in the meaningful ways for their own experiences. These would be promoted by the key universal activities which are the foundation for the students' mathematical learning. In other words, the students could recall what they have learned based on the keyuniversal activities to use as the way to solve the problems or do mathematics, and then use as resources to construct the ways of knowing or making sense for themselves. The students can regulate to do problem solving activities by themselves. Therefore, interestingly, the open approach can shift the mathematics classroom from the traditional classroom in which the teachers are the center and students only practice and drill, to a place where the students are able to do mathematics by themselves via the key universal activities.

\section{Acknowledgements}

This research is supported by the Higher Education Research Promotion and National Research University Project of Thailand, Office of the Higher Education Commission, through the 


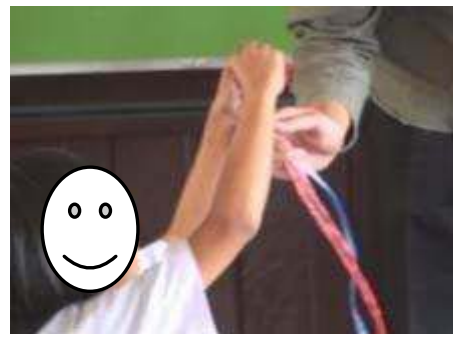

Figure 6.

Student tried to use instructional material to explain way of thinking.

Cluster of Research to Enhance the Quality of Basic Education and this research is granted by the Center for Research in Mathematics Education, Khon Kaen University, Thailand.

\section{REFERENCES}

Barell, J. (2010). Problem-based learning: The foundation for 21st Century skills. In J. Bellanca, \& R. Brandt (Eds.), 21st Century skills: Rethinking how students learn (pp. 175-200). Bloomington: Solution Tree Press.

Bellanca, J., \& Brandt, R. (Wongkitrungreuang, W., \& Jittaphreuk, A. Trans.) (2011). 21st Century skills: Rethinking how students learn. Bangkok: Openworlds.

Bishop, A. J. (1988). Mathematical enculturation. A cultural perspective on mathematics education. Dordrecht: Kluwer Academic Publishers. http://dx.doi.org/10.1007/978-94-009-2657-8
Cai, J., Mamona-Downs, J., \& Weber, K. (2005). Mathematical problem solving: What we know and where we are going. Journal of Mathematical Behavior, 24, 217-220. http://dx.doi.org/10.1016/j.jmathb.2005.09.014

Forman, E. A. (1996). Learning mathematics as participation in classroom practices: Implication of sociocultural theory for educational reform. In L. P. Steffe, \& P. Nesher (Eds.), Theory of mathematical learning (pp.115-130). Mahwah: Lawrence Erlbaum Associates.

Inprasitha, M., Pattanajak, A., \& Prakaikam, T. (2007). Context preparation for Japanese professional development called "lesson study", using in Thailand. In Proceedings of the 1st Japanese Studies Network Thailand (pp.152-163). Sangsue: Bangkok. (in Thai)

Inprasitha, M. (2008). Thailand's experience in lesson study for enhancing quality in education. In Proceedings of International Conference of Educational Research (ICER) (pp. 226-235). Khonkaen: Khon Kaen University.

Inprasitha, M., \& Isoda, M. (2010). Study with your friends. Mathematics for elementary school 1st grade. Khonkaen: Klungnana Vitthaya Press. (in Thai)

Inprasitha, M. (2010). One feature of adaptive lesson study in Thailand: Designing learning unit. In Proceedings of 45th Korean National Meeting of Mathematics Education (pp. 193-206). Seoul: Korean Society of Mathematics Education.

Inprasitha, M. (2011). One feature of adaptive lesson study in Thailand: Designing learning unit. Journal of Science and Mathematics Education, 34, 47-66.

Van Oers, B. (2002). Educational forms of initiation in mathematical culture. In C. Kieran, E. Forman, \& A. Sfard (Eds.), Learning discourse. Discursive approaches to research in mathematics education (pp. 59-85). Dordrecht: Kluwer Academic Publishers. 